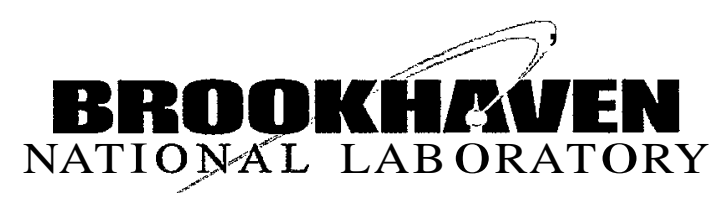

BNL-73496-2005-CP

\title{
Machine Protection System for Concurrent Operation of RHIC and BLIP
}

M. Wilinski, S. Bellavia, J.W. Glenn, L.F. Mausner, K.L. Unger

\author{
Presented at the Particle Accelerator Conference(PAC'05) \\ Knoxville, Tennessee \\ May 16-20, 2005
}

Collider-Accelerator Department

Brookhaven National Laboratory

P.O. Box 5000

Upton, NY 11973-5000

www.bnlgov

Managed by

Brookhaven Science Associates, LLC

for the United States Department of Energy under

Contract No. DE-AC02-98CH10886

This is a preprint of a paper intended for publication in a journal or proceedings. Since changes may be made before publication, this preprint is made available with the understandingthat it will not be cited or reproduced without the permission of the author. 


\section{DISCLAIMER}

This report was prepared as an account of work sponsored by an agency of the United States Government. Neither the United States Government nor any agency thereof, nor any of their employees, nor any of their contractors, subcontractors, or their employees, makes any warranty, express or implied, or assumes any legal liability or responsibility for the accuracy, completeness, or any third party's use or the results of such use of any information, apparatus, product, or process disclosed, or represents that its use would not infringe privately owned rights. Reference herein to any specific commercial product, process, or service by trade name, trademark, manufacturer, or otherwise, does not necessarily constitute or imply its endorsement, recommendation, or favoring by the United States Government or any agency thereof or its contractors or subcontractors. The views and opinions of authors expressed herein do not necessarily state or reflect those of the United States Government or any agency thereof.

FOR UNCLASSIFIED, UNLIMITED STI PRODUCTS

Available electronically at:

OSTI:

\section{http://www.osti.gov/bridge}

Available for a processing fee to U.S. Department of Energy and its contractors, in paper from:

U.S. Department of Energy

Office of Scientific and Technical Information

P.O. Box 62

Oak Ridge, TN 37831

Phone: (865) 576-8401

Facsimile: (865) 576-5728

E-mail: reports@adonis.osti.gov

National Technical Information Service (NTIS):

Available for sale to the public from:

U.S. Department of Commerce

National Technical Information Service

5285 Port Royal Road

Springfield, VA 22131

Phone: (800) 553-6847

Facsimile: (703) 605-6900

Online ordering: http://www.ntis.gov/ordering.htm

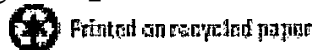




\title{
MACHINE PROTECTION SYSTEM FOR CONCURRENT OPERATIONOF RHIC AND BLIP*
}

\author{
M. Wilinski, S. Bellavia, J.W. Glenn, L.F. Mausner, K.L. Unger, BNL, Upton, NY.
}

\begin{abstract}
The Brookhaven $200 \mathrm{MeV}$ linac is a multipurpose machine used to inject low intensity polarized protons for RHIC (Relativistic Heavy Ion Collider), as well as to inject high intensity protons to BLIP (Brookhaven Linac Isotope Producer), a medical isotope production facility. If 'high intensity protons were injected to RHIC by mistake, administrativeradiation limits could be exceeded or sensitive electronics could be damaged. In the past, the changeover from polarized proton to high intensity proton operation has been a lengthy process, thereby never allowing the two programs to run simultaneously. To remedy this situation and allow concurrent operation of RHIC and BLIP, an active interlock system has been designed to monitor current levels in the AGS using two current transformers with fail safe circuitry and associated electronics to inhibit beam to RHIC if high intensity currents are detected.
\end{abstract}

\section{INTRODUCTION}

The configuration of several critical devices has prevented the BLIP and RHIC programs from running simultaneously. While the RHIC rings were being filled, the high intensity source was valved off at the linac, therefore not allowing BLIP to run. During BLIP operation, several large bending magnets were locked out to prevent high intensity protons from accidentally reaching RHIC. The lockout is a lengthy procedure and was usually only performed when operations was confident that another RHIC fill would not be needed in the short term.

To maximize the nun time of both programs and to allow concurrent operation, a dedicated pair of current transformers and various electronics were installed in the AGS. The AGS was selected as opposed to somewhere upstream, namely the linac, because the utilization of pulse-sensitive transformers in the linac would require more sophisticated electronics and timing considerations. Also, the AGS location provides a last line of defense if high intensity protons did make it that far as a result of some error.

\section{SYSTEMDESCRIPTION}

This system consists of two current transformers and their associated electronics, two interlock modules, a difference monitor, a commercial current source, current switcher, and controls hardware and software. A block diagram of the system can be seen in Figure 1.

*Work performedunder the auspices of the United States Department of Energy.

\section{Current Transformers}

Two commercial transformers were purchased from Bergoz Instrumentation [1]. They are radiation-hard New Parametric Current Transformers (NPCT) with an inner diameter of $175 \mathrm{~mm}$ and $20 \mathrm{~A} / 10 \mathrm{~V}$ full scale input. The transformers are denoted by " $\mathrm{A}$ " and " $\mathrm{B}$ in both hardware and software. A "keep-alive" circuit was also implemented that provides a current at $31.25 \mathrm{kHz}$ and $13 \mathrm{~mA}$ RMS. These transformers were installed side-byside into one enclosure at the B15 straight section of the AGS ring. ' The transformers' filters are located in a junction box just under a girder. The signals are sent to the B18 service house on $70 \mathrm{~m}$ of Belden $9508 \mathrm{NH}$ cable. The analog signals are then processed by the NPCT electronics cassettes which are installed in one $3 \mathrm{U}$ high chassis. The electronics convert the measured current to a voltage level equivalent based on the selected gain range. For operational purposes, this system uses the 2 A range.

\section{Interlock Modules}

Two Eurocard modules, one per transformer, are used to generate the interlock signals. The analog signal from the NPCT electronics is input to an interlock module which monitors the measured AGS beam and keep-alive signals. The keep-alive signal is bandpass filtered with a center frequency of $31.25 \mathrm{kHz}$, sent through a true RMSto-DC converter, and then through a window comparator to monitor its status. Based on fault studies and other administrative controls, the BNL Radiation Safety Committee has approved a maximum current level of $140 \mathrm{~mA}$ in the AGS. The measured beam signal is also sent through a comparator to determine if it is less than the approved maximum.

All trip levels are calculated based on the $2 \mathrm{~A}$ current transformer range. If the range is accidentally set to any one of the other three possible ranges, interlock signals will be generated. "The RMS keep-alive signal is equivalent to approximately $65 \mathrm{mV}$. Therefore, the keepalive window comparator levels are set to thresholds of $55 \mathrm{mV}$ and $75 \mathrm{mV}$ to avoid nuisance trips. The maximum acceptable current of $140 \mathrm{~mA}$ scales to a voltage maximum of $700 \mathrm{mV}$; the comparator for measuring the AGS beam current is therefore set to $700 \mathrm{mV}$.

This module provides outputs to two systems, the Beam Permit System (BPS) and Access Controls System (ACS), for interlocking the critical devices. The system is deemed to be in the "Okay" state if the measured current is below the $140 \mathrm{~mA}$ threshold and if the RMS keep-alive is detected within the given range. If either condition is not met, the system is in a "Failure" state. The BPS 


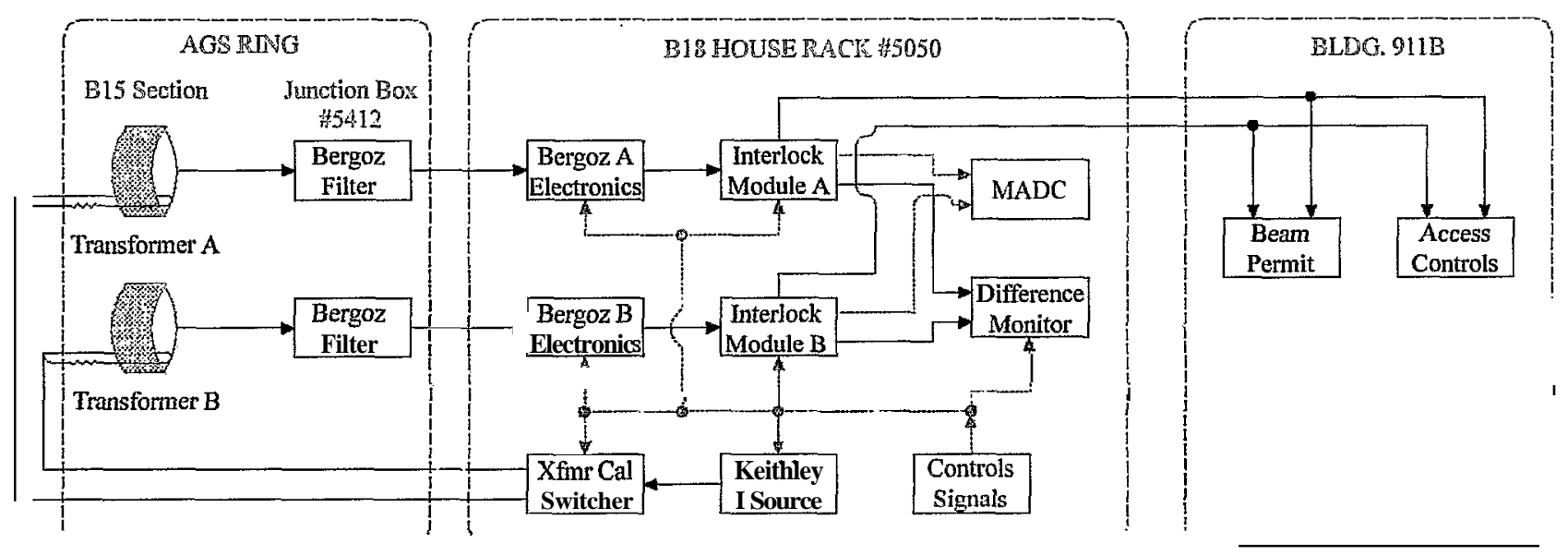

Figure 1 : System Block Diagram

receives a high signal in the Okay state and a low signal in the Failure state. In a failed state, the BPS will stop acceleration in the AGS by dropping the RF. The ACS receives a closed relay contact in the Okay state and an open relay contact in the Failure state. In a failed state, the ACS will close the Linac-to-Booster (LtB) beamstops, close the high intensity source valve, and turn off the $\mathbf{8}$ and 20 degree bending magnets in the AGS-to-RHIC (AtR) line. These systems together prevent the extraction of high intensity protons to RHIC.

\section{Difference Monitor}

Since both transformers are installed in the same location of the AGS and operate on the same gain range, they should read the same value within some tolerance. Therefore, anotherEurocard module takes a buffered copy of the transformers' signals and subtracts one from the other. The resulting difference signal is input into a window comparator to make sure both transformers are reading approximately the same value. In a failed state where the transformers are not reading the same value a warning alarm, not a machine interlock, will be generated and displayed on an alarm screen in the Main Control Room (MCR). This signifies that some attention is needed for the system and appropriate experts should be notified. The functionality for interlocking critical devices has been included in this module and could be used in the future if deemed necessary.

Since the two transformers' keep-alive circuits are not in phase, the resulting difference signal baseline is also a sinusoidal waveform. The difference was measured to be approximately $+/-185 \mathrm{mV}$, so the window has been set to $+/-250 \mathrm{mV}$. Some tolerance is given on the window to avoid nuisance warnings.

\section{Current Source and Switcher}

For testing purposes, a Keithley [2] model 238 current source is installed at the B18 House. The 238 is operated remotely through the controls system by the use of a National Instruments [3] GPIB-ENET/100, an Ethernet to GPIB controller. An independent "calibration" winding of one turn was installed around each transformer. A Eurocard switching module was built to allow the current from the 238 to be delivered to either the calibration winding for Transformer A or Transformer B. The NFCT electronics also have a calibration input that is available for testing purposes. However, this additional winding was installed to maintain independence from everything else in the system and avoid any possible interference.

\section{Controls System}

Control signals are provided by standard VME modules that are also used throughout the complex. The VME chassis is also located at the B18 House. A user interface was built into the BNL-authored controls program called pet. This can be accessed by a user from anywhere on site; one does not have to be physically in the B 18 House in order to control the system. From this interface, one can also obtain readbacks of the RMS keep-alive current and the setpoint of the maximum allowable voltage. Also a user can control the gain range, reset relays, control the Keithley 238, etc.

\section{TEST PROCEDURE}

As part of an approved procedure, the MCR operators are required to test the system once per day to ensure that all hardware and software aspects are working properly. Each test is performed for each transformer independently and all interlocks are cleared between tests.

First, all of the critical devices are turned on (if they weren't already on) to satisfy the logic conditions of the ACS. The inputs into the BPS are checked that they are enabled and not masked off.

Since the keep-alive signal can not be turned off, we can only simulate the signal going out of the monitored range. To simulate this, the gain of the transformer is changed which in turn changes the amps/volt ratio. The keep-alive signal is then out of its intended monitoring range and interlock signals are generated for this failure condition. 
The second test is to simulate an over-current condition above the maximum approved threshold. To do this, the Keithley current source is set to a value slightly above the maximum value of $140 \mathrm{~mA}$ and the current output is enabled. Again, this test causes interlock signals to be generated.

\section{RESULTSANDEXPERIENCE}

This system became operational in late March 2005. After one month of operating experience, no interlocks have occurred because of high intensity protons accidentally being injected into the AGS.

However, we did see some false trips of the system as a result of the Front-End Computer (FEC) in the controls system VME chassis automatically rebooting. The FEC was receiving a large number of hardware interrupts. After receiving a certain number of interrupts, the FEC was configured to automatically reboot. As the FEC was in the rebooting process, all digital outputs would change to their default state which caused the range of the transformers' electronics to change to 20A. Two interlocks were then generated; one for each of the transformers' keep-alive signals. This is a failure in a safe way and the system was designed to interlock when in any range other than $2 \mathrm{~A}$. To solve this problem, interrupts were turned off for all of the extra unused channels. After this change was made, there have been no further false failures as a result of the VME automaticallyrebooting.

Another unexpected difficulty arose in the Difference Monitor module. The difference signal was experiencing some drift and the voltage levels for the window comparator would have to be adjusted on almost a weekly basis. Prior to adjustment for the drift, the FEC's memory would often be low as it would be logging many out-ofrange messages. Also, there was a $60 \mathrm{~Hz}$ sinusoid appearing on only one input to the difference monitor module. After investigation, it was discovered that a $-15 \mathrm{~V}$ pin on a buffer that fed the input signal was never soldered to the circuit board pad during the fabrication process. Upon repair of that error, the $60 \mathrm{~Hz}$ signal is no longer present and the difference signal has stabilized.

Figures 2 and 3 depict output signals from the current transformers. Figure 2 is an oscilloscope trace of the keep-alive signal structure. Figure 3 is a trace of copper beam in the AGS. At first glance the signal seems to be extraordinarily noisy. In reality, it is not noise but is the $31.25 \mathrm{kHz}$ keep-alive signal riding on top of the beam signal.

\section{ACKNOWLEDGEMENTS}

Many people have made contributions to the fabrication, installation, and operation of this system and we thank: A. Curcio, S. Jao, D. Kipp, D. Meany, B. Oerter, T. Russo, W. Venegas, and P. Ziminski

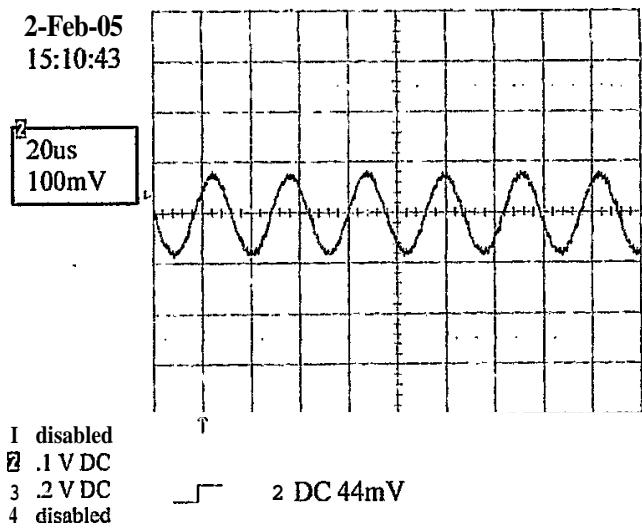

$1 \mathrm{GS} / \mathrm{s}$

Figure 2 Keep-Alive signal

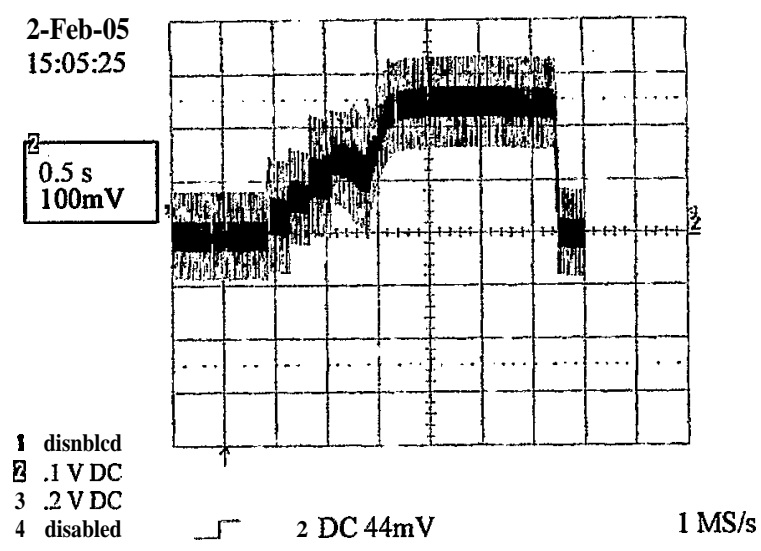

Figure 3: Beam Current Signal

\section{REFERENCES}

[1] http://www.bergoz.com

[2] http://www.keithley.com

[3] http://www.ni.com 